Nig. J. Biotech. Vol. 37(1): 150-158 (June 2020)

ISSN: 01891731

Available online at

http://www.ajol.info/index.php/njb/index

and www.biotechsocietynigeria.org

DOI: https://dx.doi.org/10.4314/njb.v37i1.16

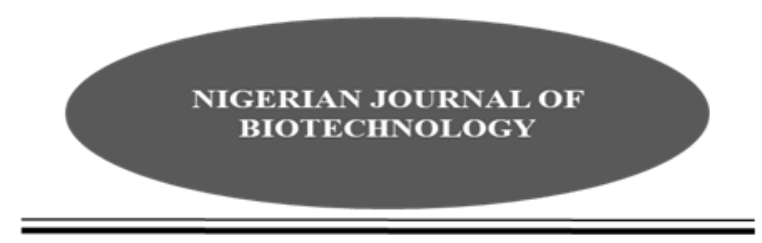

\title{
Effects of different media strengths and hormone concentrations on in-vitro regeneration of Vitellaria paradoxa C.F. Gaertn
}

\author{
Afolabi, J.O., Olorode, E.M., Olomola, D.B., Fasakin, Y.O. and Adekunle, E.A* \\ Biotechnology Section, Bioscience Department, Forestry Research Institute of Nigeria. P.M.B 5054, \\ Ibadan, Nigeria.
}

\begin{abstract}
The importance of Vitellaria paradoxa has necessitated its inclusion in the ongoing afforestation project which requires mass production of its seedlings. The shea-butter tree produces oil-rich seeds that are important to cosmetic and food and nutrition industries. It is a deciduous tree which could survive in the dry-savannah and help withstand desert encroachment. However, overexploitation of its timber for firewood and charcoal production made it vulnerable. In-vitro propagation of this species could be a viable means towards its mass propagation. Two plant-hormones: Gibberellic Acid (GA3) and Benzyl Amino Purine (BAP) were used to grow the plant in different combinations making up six treatments (A-F) with 6 replicates in each group. The combinations include 1.5/0, 1.5/1.0, 1.5/1.5, 2.0/0, 2.0/1.0, $2.0 / 1.5 \mathrm{mg} / \mathrm{L}$ of $\mathrm{GA}_{3} / \mathrm{BAP}$, which were used to grow $2 \mathrm{~cm}$ nodal cuttings of the $V$. paradoxa on half-strength Murashige and Skoog (MS) media. Treatment $F$ (with 2.0/1.5 mg/L GA3/BAP) produced the highest number of leaves $(2.4 \pm 0.6,3.2 \pm 0.8)$ and longest shoot length $(1.1 \pm$ $0.3 \mathrm{~cm}, 1.4 \pm 0.5 \mathrm{~cm}$ ) at 4 and 8 Weeks After Inoculation (WAI), respectively. The results of this study showed that application of growth- enhancing hormones for the regeneration of important tree species could provide means for their mass propagation so as to meet the need for afforestation projects.
\end{abstract}

Keywords: Vitellaria paradoxa, Afforestation, In-vitro propagation, Mass propagation.

*Corresponding author: adekunleea@gmail.com, adekunle.ea@frin.gov.ng

\section{Introduction}

Vitellaria paradoxa commonly referred to as the shea butter tree is of the family Sapotaceae, and grows well in the savannah region of West Africa. The tree is of great economic importance due to its multipurpose use (Yakubu et al., 2015). It serves as a fruit tree as well as an oil seed crop. It is popular for the shea butter produced from it, which is relevant in the food, cosmetic and pharmaceutical industries (Boffa, 2015). Due to its ability to produce fatty seeds, $V$. paradoxa is used in the manufacture of soap, body cream. Medicinally, it is used in preparation of topical creams for the treatment of bone dislocation, carbuncles and cough (Maanikuu and Peker, 2017). It is also used for carving of mortar and pestle because of its hardness, resistance to borers and durability (Abdullahi, 2013).

The growing demand for shea butter both for local and industrial use call for necessary domestication and management of the shea tree. However, overexploitation of its timber for firewood and charcoal production has brought the current International Union for Conservation of Nature and Natural Resources (IUCN) status of the tree from near threatened to vulnerable (IUCN, 2018). Populations of shea butter trees are from natural regeneration, unprotected and wild- managed cultivation. Cross-pollination of these wild-managed stands has resulted in heterozygous individuals, and produce an unreliable crop in terms of quantity and quality (Lovett and Haq, 2013). The growing importance of this tree species, cutting 
for fuel wood, the threat of over-harvesting and the need to produce superior true-to-type varieties in order to capture superior genetic traits prompted research into the clonal propagation of this tree (Ræbild et al., 2011).

However, vegetative methods, such as grafting, budding, cuttings and air-layering, have only produced limited success (Frimpong and Adomako, 1989; Yeboah et al., 2010). The micro propagation of woody tree species is now a method widely used in the regeneration and conservation of germplasms (Lovett and Haq, 2013). Therefore, the aim of this study is to develop a protocol for the in vitro propagation of $V$. paradoxa and to determine the effect of growth elicitors for the regeneration of the tree species as a veritable mean to overcome the problem of slow germination rate and maturity

\section{Materials and Methods}

All the media used were prepared following standard procedures: MS according to Murashige and Skoog, (1962), Woody plant medium (WPM) (Lloyd and McCown, 1981), Preece (Pr) (Preece et al., 1989) and DKW (Driver and Kuniyuki, 1984). The media pH were adjusted to 5.8 , gelled by $0.7 \mathrm{~g} / \mathrm{L}$ Agar and $15 \mathrm{ml}$ of each medium was dispensed into tubes of $2.5 \mathrm{~cm} \times 15 \mathrm{~cm}$. The media were autoclaved at $121^{\circ} \mathrm{C}$ for $15 \mathrm{~min}$.

The nodal cuttings used as explants were sourced from a well-managed stock of $V$. paradoxa seedlings kept in the screen-house. The seedlings were treated with a fungicide (10\% Carbendazim), $24 \mathrm{~h}$ before explant collection, to reduce its microbial load.

Surface sterilization of the explants was carried as follows; $\approx 2 \mathrm{~cm}$ shoots were collected from the stock of $V$. paradoxa under management. The explants were washed under a flowing tap for $15 \mathrm{~min}$ and were later taken to laminar air flow hood for surface sterilization. The explants were dipped in $0.3 \%$ Ascorbic acid for $3 \mathrm{~min}$. They were then dipped in amoxycillin solution of $0.2 \mathrm{~g} / \mathrm{L}$ for $5 \mathrm{~min}$ followed by the addition of $70 \%$ ethanol for 60 sec. The explants were rinsed with sterile distilled water 3 times after each treatment with each ascorbic acid, amoxycillin and ethanol. 2 drops of Tween 20 was added together with $3 \%$ Sodium hypochlorite for 20 min and then rinsed 5 times with distilled water. The explants were then placed on sterilized filter paper in petri-dish to dry before being inoculated on the media. The inoculated explants were kept in the growth room under $16 / 8 \mathrm{~h}$ light/dark photoperiod.

The MS (100\% basal salts) medium was supplemented with two growth regulators $\mathrm{GA}_{3}$ and Bap to determine the effects of different growth regulators on sprouting and shoot regeneration of $V$. paradoxa. The first treatment consists of $\mathrm{GA}_{3} / \mathrm{BAP}$ of different concentrations: $1.5 / 0,1.5 / 1.0,1.5 / 1.5,2.0 / 0$, 2.0/1.0, 2.0/1.5 mg/L. The second treatment comprised MS ( $50 \%$ basal salts) medium with the same hormone treatments. Effect of different media on shoot regeneration of $V$. paradoxa was studied by inoculating the plant on 4 different media (MS, WPM, Preece and DKW). In each case, $100 \%$ (Full strength, FS) and $50 \%$ (Halfstrength, HS) were used and this resulted in 8 treatments. However, all the treatments in this experiment were supplemented with $\mathrm{GA}_{3} / \mathrm{BAP} 2.0 / 1.0 \mathrm{mg} / \mathrm{L}$ being the optimal hormonal concentration obtained from the first experiment.

Biometric indices (Shoot length [SL] and Number of leaves, [NL]) were recorded on the plantlets at 4, 8 and 12 Weeks After Inoculation (WAI). The data collected were subjected to analysis of variance using the GenStat package (Edition 4) while significantly different means were separated using Duncan Multiple Range Test (DMRT).

\section{Results}

Effect of MS (100\% basal salts) medium supplemented with GA and BAP on shoot regeneration of $V$. paradoxa

The results of the different combinations and concentrations of $\mathrm{GA}_{3}$ and BAP supplemented in $100 \%$ basal salts of MS medium showed that all the hormonal combinations used encouraged $\mathrm{V}$. paradoxa shoot growth and average number of leaves. Addition of $2.0 / 1.5 \mathrm{mg} / \mathrm{L} \mathrm{GA}_{3} / \mathrm{BAP}$ to the media induced higher number of leaves at 8 and 12 weeks after inoculation (WAI) (Fig 1a, plate $1 \mathrm{~F}$ ) while the medium supplemented with $1.5 / 1.5 \mathrm{mg} / \mathrm{L}$ of $\mathrm{GA}_{3} / \mathrm{BAP}$ produced the least number of leaves. The MS ( $100 \%$ basal salts) medium supplemented with $\mathrm{GA}_{3} / \mathrm{BAP}$ also shows similar results; it encouraged axill ary growth of $V$. paradoxa. Formation of adventitious shoot in this experiment was more pronounced in 2.0/1.5 mg/L GA3/BAP treatment (Fig 1b, Plate 1F). In all the treatments, biometric indices (number of leaves and axill ary shoot length) were 
higher at 12 WAI relative to those obtained at 8 WAI.

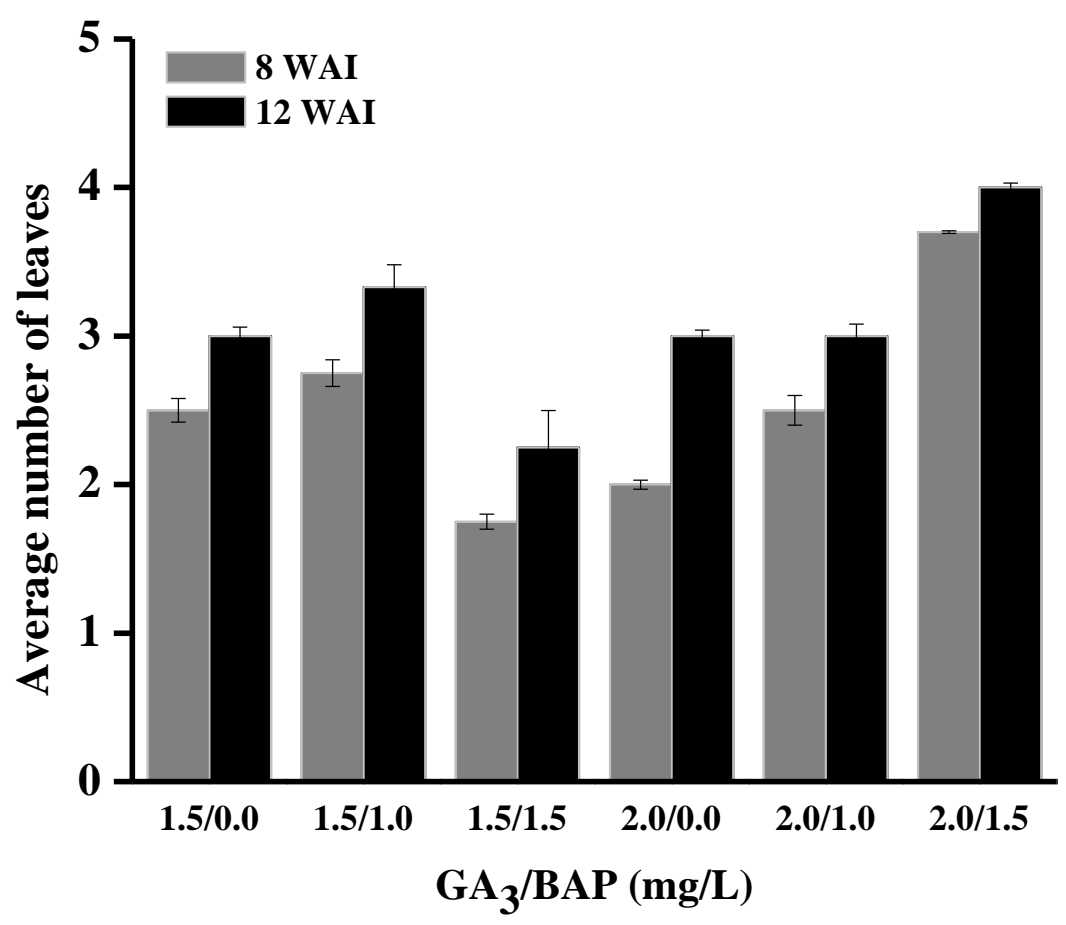

Fig 1a: Effect of MS (100\% basal salts) medium supplemented with $\mathrm{GA}_{3} \quad$ /BAP on number of leave regeneration of $V$. paradoxa

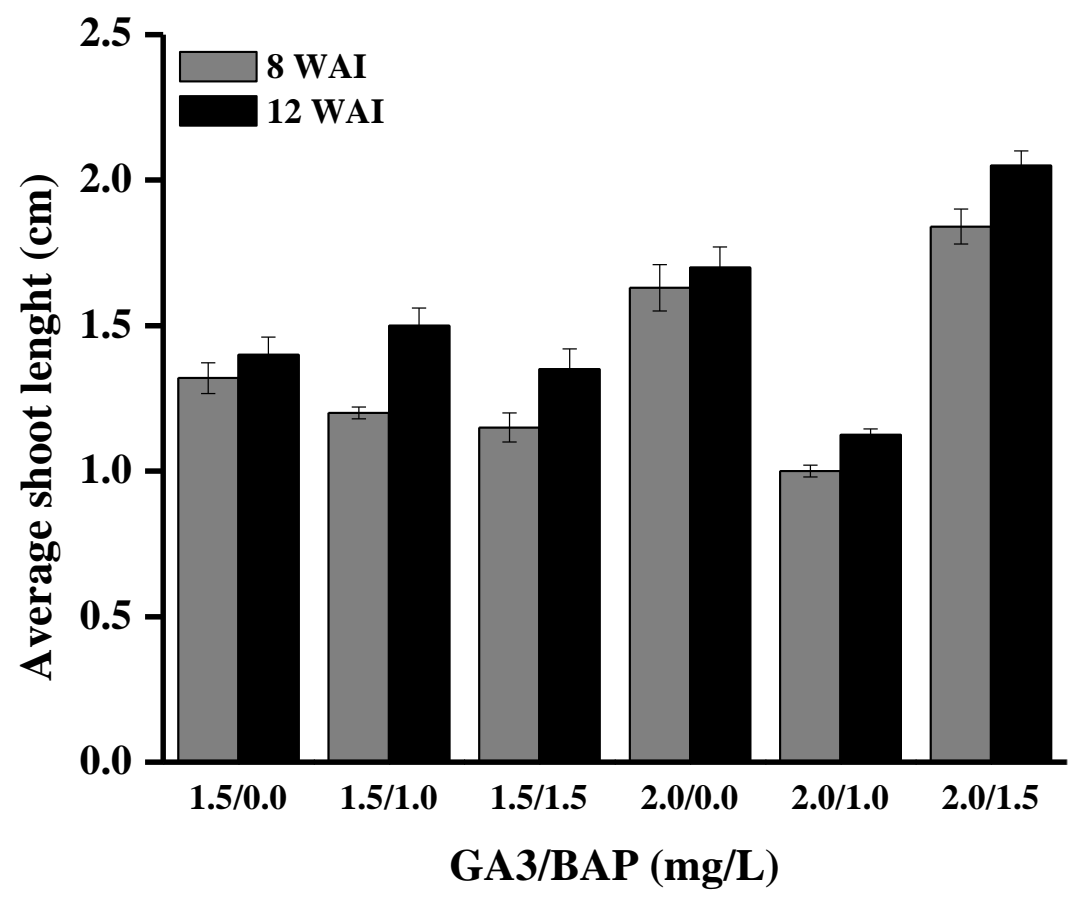


Fig 1b: Effect of MS (100\% basal salts) medium supplemented with $\mathrm{GA}_{3} \quad$ /BAP on shoot length of $V$. paradoxa

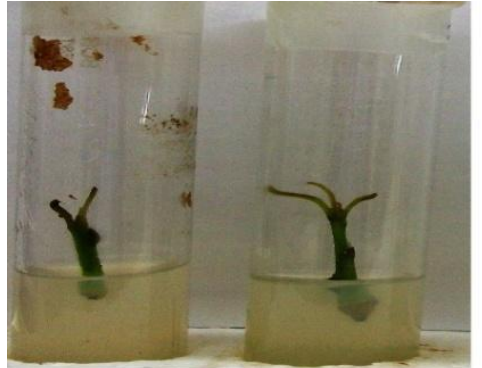

A

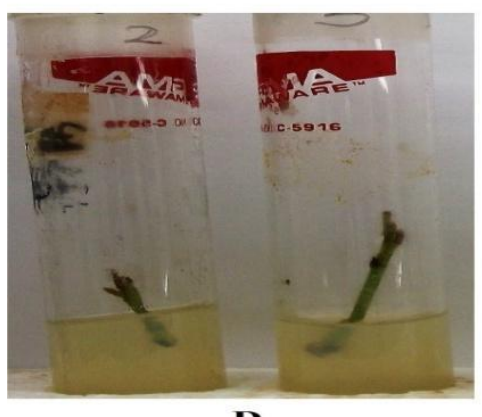

D

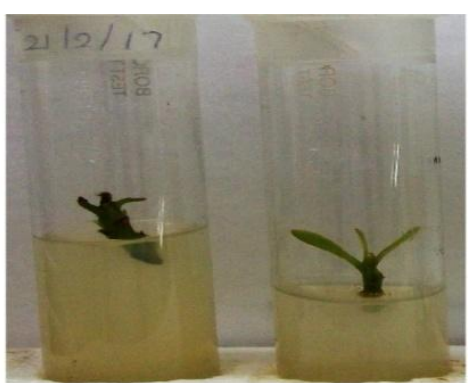

B

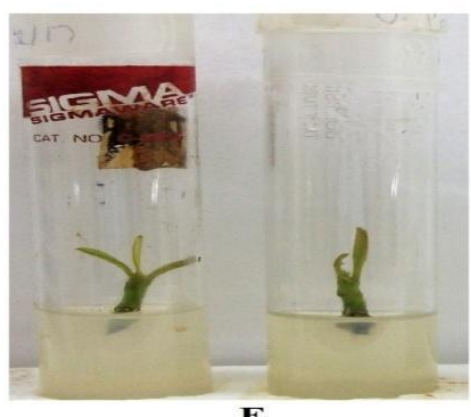

E

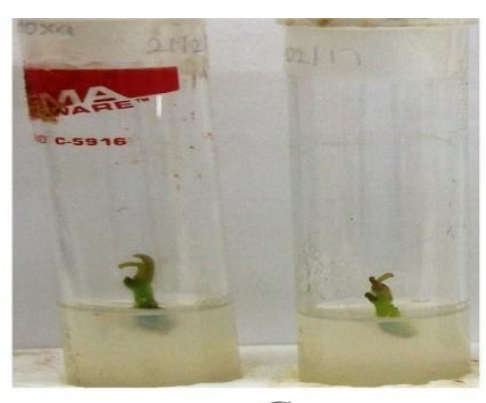

C

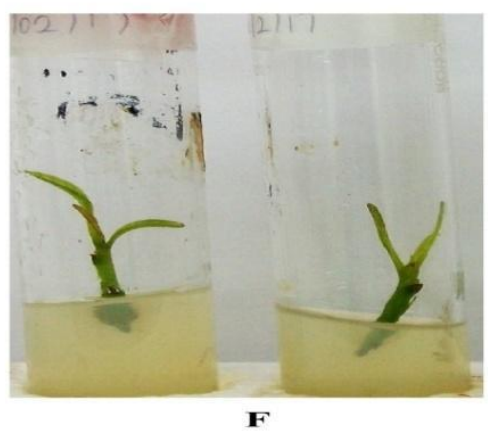

Plate 1: Growth and development of V. paradoxa plantlets on MS (100 \% basal salts) medium supplemented with A: $1.5 / 0$,

B: $1.5 / 1.0$, C:1.5/1.5, D: 2.0/0.0, E: 2.0/1.0 and F $2.0 / 1.5 \mathrm{mg} / \mathrm{L}$ $\mathrm{GA}_{3} / \mathrm{BAP}$

Effect of MS (50\% basal salts) medium supplemented with $G A_{3}$ and $B A P$ on shoot regeneration of $V$. paradoxa

The results of $V$. paradoxa inoculated on half strength MS medium are presented in Figures 2 $a \& b$ and Plate $2(A-F)$. Utilization of $50 \%$ MS basal salt with the various hormonal combinations induced leaves and shoots regeneration in V. paradoxa explants. At 4 WAI, the biometric indices were more prominent than those observed in the first treatment trial. Generally, the number of leaves induced by the hormonal treatments at 4 WAI increased till 8 WAI (Fig 2 a, Plate 2). The NL recorded in the treatment supplemented with $2.0 / 1.5(\mathrm{mg} / \mathrm{L})$ $\mathrm{GA}_{3} / \mathrm{BAP}$ were $2.16 \pm 0.75$ and $3.4 \pm 0.54$ at 4 and 8 WAI, respectively. These values were not significantly different from the NL obtained from the same hormonal concentration in the $100 \% \mathrm{MS}$ at the $12^{\text {th }}$ WAI (Table 1). The highest shoot length (SL) measurement was recorded in the media supplemented with 2.0/1.0 GA3/BAP (mg/L). 


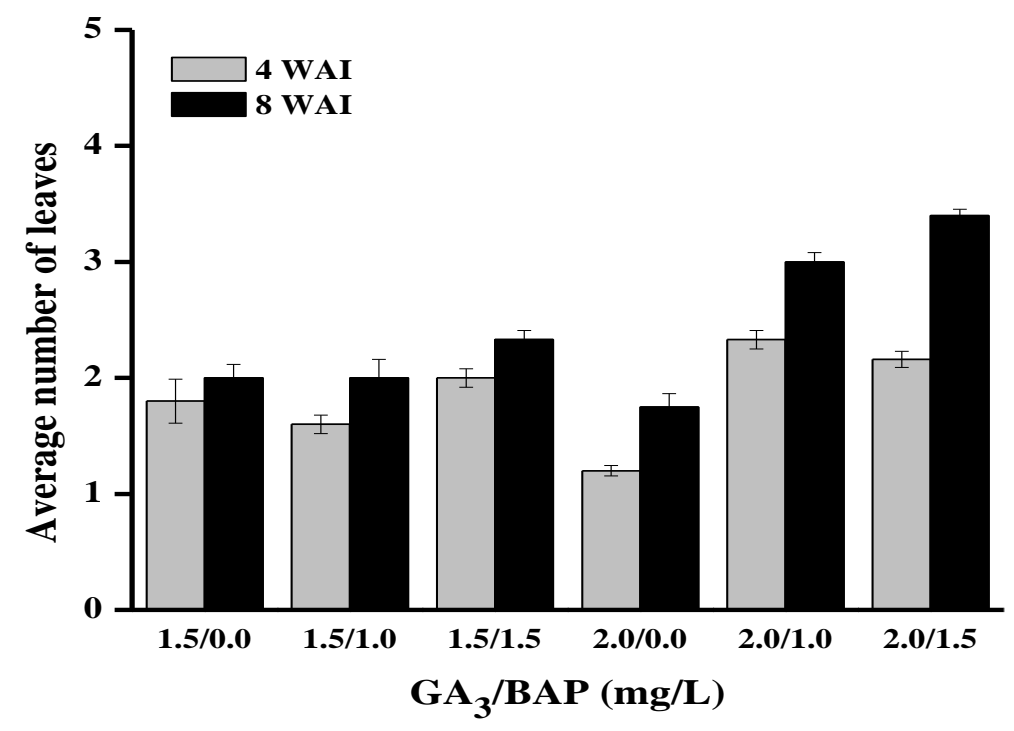

Fig 2a: Effect of MS ( $50 \%$ basal salts) medium supplemented with $\mathrm{GA}_{3} \quad$ /BAP on the number of leaves of V. paradoxa regenerated

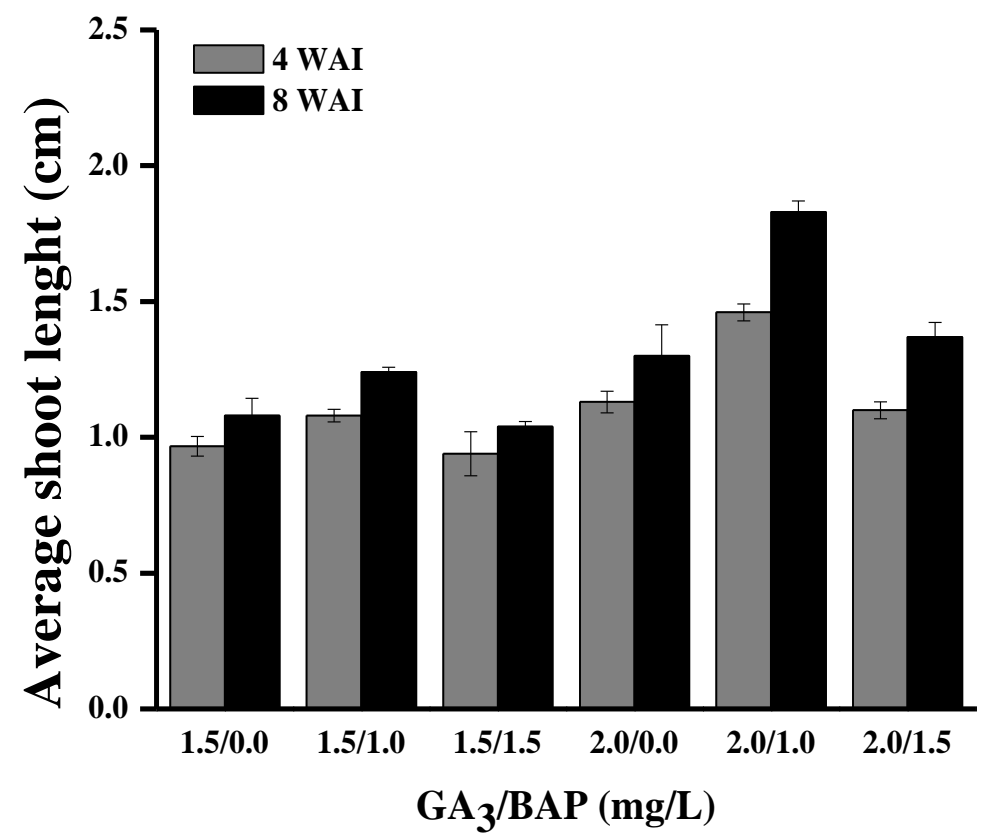

Fig 2b: Effect of MS ( $50 \%$ basal salts) medium supplemented with $\mathrm{GA}_{3} \quad$ /BAP on shoot length of $\quad V$. paradoxa 


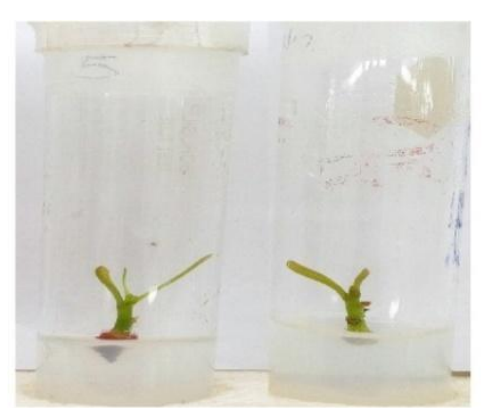

$\mathbf{A}$

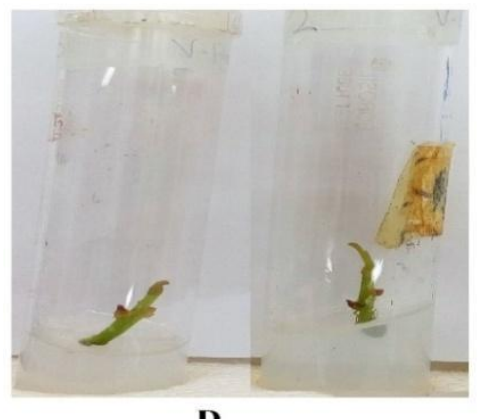

D

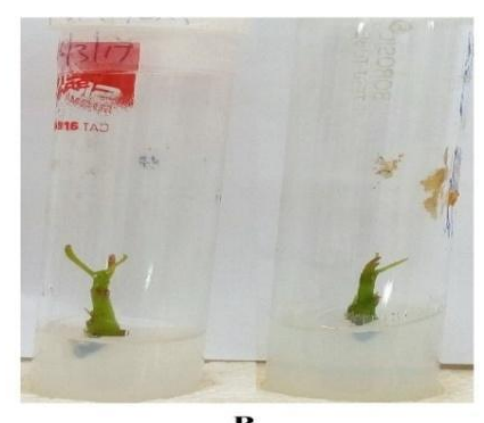

B

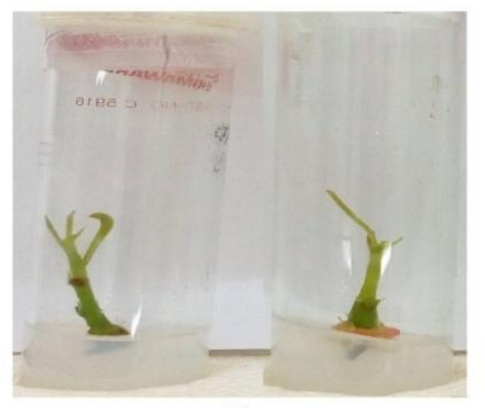

$\mathbf{E}$
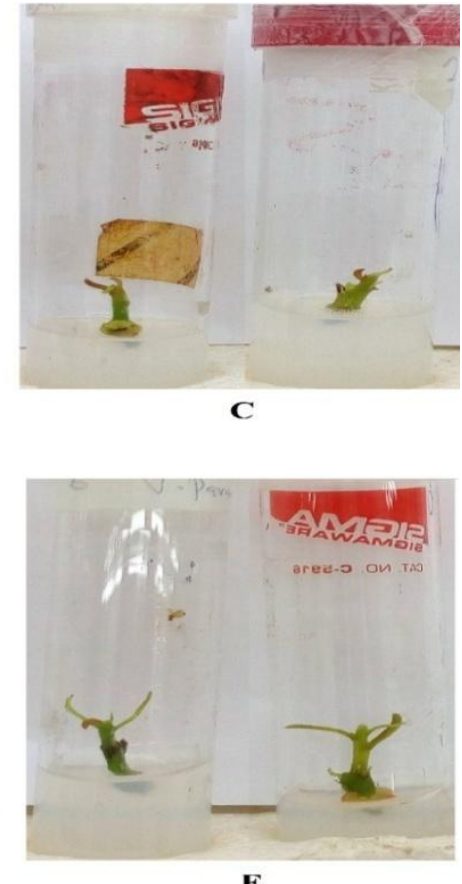

$\mathbf{F}$

Plate 2: Growth of $V$. paradoxa plantlets on MS ( $50 \%$ basal salts) medium supplemented with 1.5/0 , B: $1.5 / 1.0$, C:1.5/1.5, D: 2.0/0.0, E: $2.0 / 1.0$ and F 2.0/1.5 mg/L GA $3 /$ BAP

Effects of media types and media strengths on the number of leaves and shoot lengths of $V$. paradoxa

The effect of media types and strengths is presented in Table 1. The results showed that there was a significant difference in the average number of leaves (NL) obtained at 4 and 8 WAI. The NL produced by MS medium was similar to those obtained from DKW but significantly higher than the NL obtained from WPM and Preece media. At 4 WAI, there was no significant difference between the NL produced in WPM and Preece media. Results of the effect of media type on NL at 8 WAI showed that the highest NL were obtained from DKW medium. The order of total NL obtained from the different media used for these experiments was DKW $>$ MS > WPM > Pr. In addition, the effect of media strengths on NL showed that reducing the nutrient concentration of the media by half ( $50 \%$ basal salt) increased leaf production.

On the other hand, using different media strengths did not result in any significant variation in the shoot length (SL) as observed during the period of growth. Although there was no significant difference in the effect of media types on the SL of $V$. paradoxa, DKW medium produced longer SL compared to the other media at 8 WAI. The full ( $100 \%$ basal salt) strength produced higher SL than the half (50\% basal salts) strength (Table 1 ).

Table 1: Effects of media types and media strengths on the growth of regenerated V. paradoxa

\begin{tabular}{|c|c|c|c|c|c|}
\hline \multirow{2}{*}{ Treatments } & & \multicolumn{2}{|c|}{ Number of leaves (NL) } & \multicolumn{2}{|c|}{ Shoot length (SL) } \\
\hline & & 4 WAI & 8 WAI & 4 WAI & 8 WAI \\
\hline Media type & $\begin{array}{l}\text { MS } \\
\text { WPM } \\
\text { PREECE }\end{array}$ & $\begin{array}{l}2.50 a \\
1.50 b \\
1.18 b\end{array}$ & $\begin{array}{l}2.75 a b \\
1.90 b c \\
1.45 c\end{array}$ & $\begin{array}{l}0.90 \\
0.93 \\
0.82 \\
\end{array}$ & $\begin{array}{l}1.08 \\
1.18 \\
1.29 \\
\end{array}$ \\
\hline
\end{tabular}




\begin{tabular}{llllll}
\hline \multirow{2}{*}{ Media strength } & DKW & $2.43 a$ & $3.05 a$ & 1.18 & 1.5 \\
& Full & 1.79 & 2.13 & 0.93 & 1.28 \\
& Half & 2.02 & 2.45 & 0.98 & 1.24 \\
S.E.D @ p $\leq 0.05$ & & & & & \\
Media types x Media strengths & Ns & 1.23 & ns & ns \\
\hline
\end{tabular}

\section{Media types and media strengths interaction}

The relationship between treatment levels and response variables were analysed to determine the effectiveness of the treatments. There was a significant difference $(P \leq 0.05)$ in the interactive effects of media types and media strengths on the average number of leaves $(\mathrm{NL})$ at $8 \mathrm{WAI}$ (Table 1 and plate 3). DKW medium at half strength produced a similar NL to MS. At equal strength, both media (DKW and MS) produced significantly higher NL than when other media were used at either of the strengths (Figure 3).

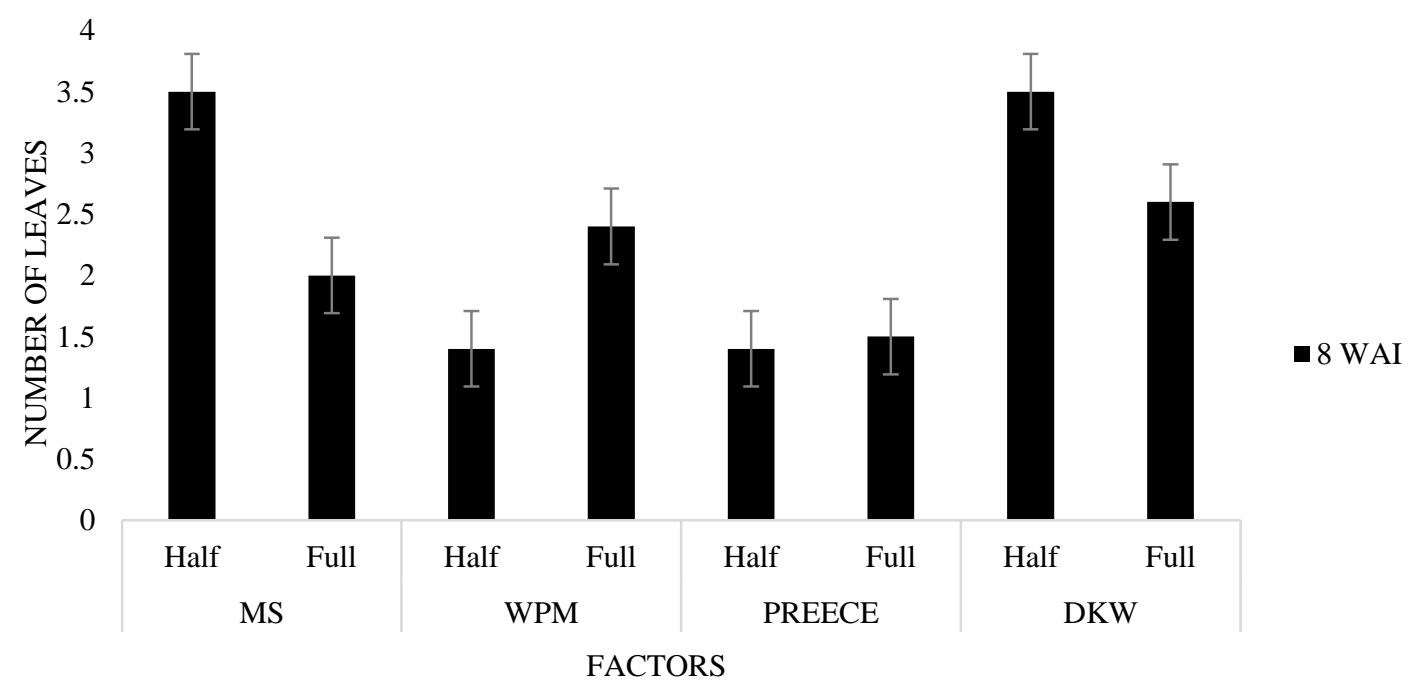

Fig 3. Effect of media types at average levels of media strengths on the number of leaves at the successive growth periods.

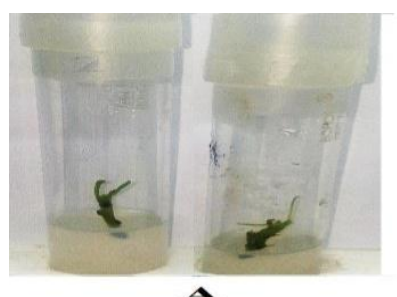

A

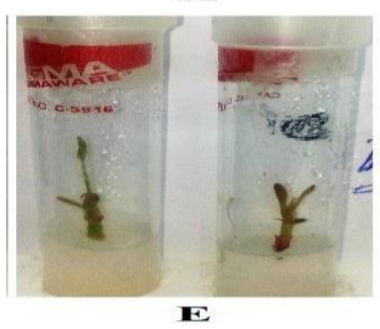

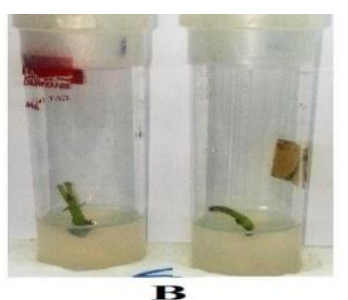

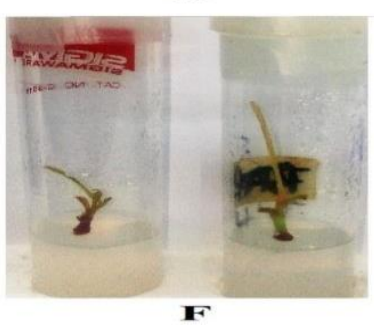

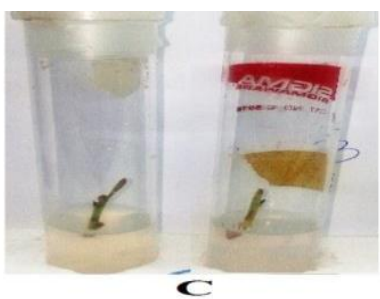

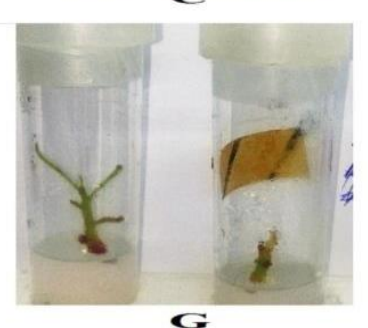

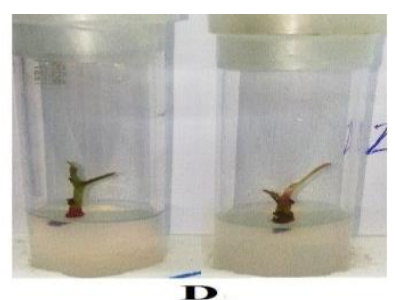

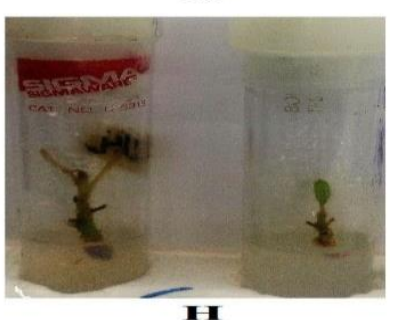

Plate 3: Growth of $V$. paradoxa plantlets on different media and strengths

A: MS at HS; B: MS at FS; C: WPM HS; D: WPM at FS E: Preece at HS; F: Preece at FS 
G: DKW at HS H: DKW at FS (HS - Half strength, FS - Full Strength)

\section{Discussion}

The use of appropriate heterocyclic compounds as plant growth regulators is one of the factors that could influence plant growth. Plants regeneration efficiency depends on the medium composition: macro- and micronutrients, type and concentration of growth regulators, and carbon source (Ilczuk andJacygrad, 2016). In this study, the effects of MS at full and half strength in the presence of plant growth regulators in media supplemented with $\mathrm{GA}_{3}$ /BAP on leaf regeneration and shot length showed that MS at half-strength performed better. The media possibly exhibited inhibitory function at full strength due to excessive ion concentration (Bell et al., 2009).

The growth hormones used in this work are cytokines known for stimulating the development of axill ary shoot (Dobranszki et al., 2010). Lots of studies have used cytokines for in vitro shoot propagation of various woody plants and medicinal plants (Ostrolucka et al., 2007; Arab et al., 2014 and Shekhawat et al., 2015). Combinations of the cytokines used in different proportions affected the growth in different patterns. The variation in the plants response pattern could be attributed to nonuniformity in totipotency and its ability to respond to epigenetic signals which are some of the factors responsible for shoot formation (Thorpe et al., 2008). Appropriate concentration of the cytokines controls the plant's morphogenesis and transition from G1 to $S$ phases of the cell cycle (Gahan, 2007). The levels of cytokines used at various combinations in this work encouraged the plant shoots and leaves to increase as the experiment progressed. Lovett and Haq, (2013) reported similar increase in shoot length of $V$. paradoxa propagated in media supplemented with different ratios of 6-benzyladenine (BA) and Naphthaleneacetic acid (NAA). Also, Ashraf et al., (2014) reported that combination of two different cytokines produced a higher number of shoots and higher shoot lengths compared to the singular effects of the individual hormones. This is similar to our observation in this study. The different media types and media strengths the enhanced growth indices in the order DKW > MS > WPM > Preece. DKW resulted in the best proliferation probably due to its nitrogen content relative to the other media. Overall, shoot proliferation in plants has been shown to be dependent on carbon to nitrogen ratio in media used (Franklin and Agren, 2003; Razaq et al., 2017).

\section{Conclusion}

In vitro propagation of tree species could serve as a viable alternative for raising woody plants with propagation difficulties. Application of appropriate hormones in the right proportion could also enhance tree growth response. Continuous efforts and research are needed to be in place to achieve a sustainable protocol for the propagation of highly economic forest tree species such as $V$. paradoxa. When such efforts yield the desired result, it will go a long way to sustain the availability of these economic trees, as well as prevent their extinction.

Conflict of Interest: The authors declare that they have no conflict of interest.

\section{References}

Abdullahi, I. N. (2013). Biotechnology Application for the Improvement of Nigeria's Indigenous Tree Species: The Challenges of Micropropagation. Int. J. Sci. Res. Environ. Sci. 1(6): 107-114. ISSN: 2322-4983.

Arab, M. M., Yadollahi, A., Shojaeiyan, A., Shokri, S. and Ghojah, S. M. (2014). Effects of nutrient media, different cytokinin types and their concentrations on in vitro multiplication of G - N15 (hybrid of almond peach) vegetative root stock. J.Genet. Eng. Biotechnol. 12: 81-87.

Ashraf, M.F., Abd-Aziz, M., Kemat, N. and Ismail, I. (2014). Effect of cytokinin types, concentrations and their interactions on in vitro shoot regeneration of ChlorophytumborivilianumSant.\& Fernandez. Electron. J.Biotechnol. 17: 275-279.

Bell, R.L., Srinivasan, C. and Lomberk, D. (2009). Effect of nutrient media on axillary shoot proliferation and preconditioning for adventitious shoot regeneration of pears. Vitr. Cell. Dev. Biol. - Plant. 45: 708-714.

Boffa, J.M. (2015). Opportunities and challenges in the improvement of the shea (Vitellariaparadoxa) resource and its management. Occasional Paper 24. Nairobi: World Agroforestry Centre. 
Dobranszki, J. andTeixeira da-Silva, J.A. (2010). Micropropagation of Apple. Biotechnol. Adv. 28: 462-488.

Driver, J.A. and Kuniyuki, A.H. (1984). In vitro propagation of Paradox walnut rootstock. Hort. Sci. 19: 507-509.

Dupriez, H. and DeLeener, P. (1989). African gardens and orchards: growing vegetables and fruits, Macmillan Press Ltd., London, UK.

Franklin, O.and Agren, G. I. (2003). Root: Shoot Ratios, Optimization and Nitrogen Productivity. Ann. Bot. 92(6): 795-800.

Frimpong, E.B. and Adomoko, D. (1989). Vegetative propagation of shea, kola andPentadesma. Cocoa Research Institute (Ghana Academy of Science) Annual Report.1985/86:100.

Gahan, P.B. (2007). Totipotency and the cell cycle in Protocols for Micropropagation of Woody Trees and Fruits.S.M. Jain and $\mathrm{H}$. Häggman (eds.), Protocols for Micropropagation of Woody Trees and Fruits, 314.Springer.

Ilczuk, A. and Jacygrad, E. (2016). In vitro propagation and assessment of genetic stability of acclimated plantlets of Cornusalba L. using RAPD and ISSR markers. Vitr. Cell. Dev. Biol. Plant.52 (4):379-390.

IUCN (2018). Vitellaria paradoxa. The IUCN Red List of Threatened Species. http://dx.doi.org/10.2305/IUCN.UK.1 998.RLTS.T37083A10029534.en. Acessed on 04 July 2018.

Lovett, P. N. and Haq, N. (2013). Progress in developing in vitro systems for shea tree (Vitellaria paradoxa C.F. Gaertn.) propagation. For. Trees Livelihoods .1-19.

Maanikuu, P.M.I. andPeker, K. (2017). Medicinal and Nutritional Benefits from the Shea Tree (Vitellariaparadoxa). J. Biol. Agric. Healthcare. 7(22). Pp.51-57

Murashige, T. and Skoog, F. (1962). A revised medium for rapid growth and bioassays with tobacco cultures. J.Plant Physiol. 15: 473-497.

Ostrolucka, M. G., Gajdosova, A. andLibiakova, G. (2007). Protocol for micropropagation of Guercusspp. S.M. Jain and H. Häggman (eds.), Protocols for Micropropagation of Woody Trees and Fruits, 85-91. Springer.
Preece, J.E., Van Sambeek, J.W., Huetteman, C.A. and Gaffney G.R. (1989). Biotechnology: in vitro studies with walnut (Juglans) species. In: Phelps JE (ed) The continuing quest for quality. Proceeding of 4th Black Wal- nut Symposium, Walnut Council, Indianapolis, pp $159-180$.

Ræbild, A., Larsen, A.S., Jensen, J.S., Ouedraogo, M., De Groote, S., Van Damme P., Bayala, J., Diallo,B.O., Sanou, H., Kalinganire, A. and Kjaer, E.D. (2011). Advances in domestication of indigenous fruit trees in the West African Sahel. New Forest. 41:297-315.

Razaq, M., Zhang, P., Shen, H. I. andSalahuddin, A. (2017). Influence of nitrogen and phosphor us on the growth and root morphology of Acer mono. PLoS One. 12(2): e0171321. doi:10.1371/journal. pone.0171321.

Shekhawat, M. S., Kannan, N., Manokari, M. andRavindran, C.P. (2015). In vitro regeneration of shoots and ex vitro rooting of an important medicinal plant Passiflora foetida L. through nodal segment cultures.J. Genet. Eng. Biotechnol. 13, 209-214.

Thorpe, T., Stasolla, C., Yeung, E.C., de Klerk, G.J. and Roberts, A. and George E.F. (2008)in: E.F. George, M.A. Hall, G.J, De Klerk (Eds.) (2008). Plant Propagation by Tissue Culture, Springer. pp. 115-173.

Yakubu, F.B., Asinwa, I.O.,Shodeke, D.K. A, Williams, O.A. and Obekpa, N.B. (2015). Effects of NPK fertilizer on the shoot growth of Vitellaria paradoxa C.F. Gaertn. African J. Environ. Sci. Technol. Vol. 9 (1), pp.8-11. DOI. 10.5897/AJEST09.171

Yeboah, J., Akrofi, A. Y. and Owusu-Ansah, F. (2010). Influence of selected fungicides and hormones on the rooting success of shea (Vitellaria paradoxa Gaertn) stem cuttings. Agric. Biol. J. Nor. Am. (3):313-320. 